\title{
MODERNIZAÇÃO DOS CRIMES SEXTING E REVENGE PORN: NO AMBIENTE VIRTUAL CONTRA A MULHER
}

\author{
MODERNIZATION OF SEXTING AND REVENGE PORN CRIMES: IN THE VIRTUAL \\ ENVIRONMENT AGAINST WOMEN
}

\section{Bruna Larissa Campos de Oliveira ${ }^{1}$ \\ Andréia Alves de Almeida ${ }^{2}$}

RESUMO: Este estudo buscou verificar representações sociais das mulheres que sofrem ou sofreram algum tipo de violência Sexting Revenge Porn, buscando entender a subjetivação desse fenômeno, como também verificar os o Direito Penal em um delegacia de Polícia na Região Sul do Amazonas no Município de Humaitá e foram feitas análises de registro de ocorrência. Como resultado foi constatado que a maior prevalência é a violência doméstica. Verificou-se também que o ciclo de violência é alimentado pela tolerância e auto culpa e pela má compreensão da mesma. Propõem-se outros estudos nesta esfera com finalidade de maior compreensão do fenômeno da violência contra as mulheres.

Palavras-chave: Crimes. Mulher. Violência.

ABASTRACT: This study sought to verify the social representations of women who suffer or have suffered some type of Sexting Revenge Porn violence, seeking to understand the subjectivation of this phenomenon, as well as verifying the Criminal Law in a Police Station in the South Region of Amazonas in the Municipality of Humaitá. occurrence log analyses. As a result, it was found that the highest prevalence is domestic violence. It was also found that the cycle of violence is fueled by tolerance and self-blame, and by a misunderstanding of it. Further studies in this sphere are proposed with the aim of better understanding the phenomenon of violence against women.

Keywords: Crimes. Women. Violence.

\footnotetext{
I Graduanda do curso de Direito - União das Escolas Superiores de Rondônia - UNIRON. E-mail: brunalari.coliveira@gmail.com

${ }^{2}$ Doutorado em Ciência Jurídica Interinstitucional UNIVALI/Faculdade Católica de Rondônia, 2015/19, Mestre em Direito A mbiental pela Fundação de Ensino Eurípides Soares da Rocha (2006). Especialista em Direito Penal pelas Faculdades Integradas "Antônio Eufrásio de Toledo (2003). Especialista em Segurança Pública e Direitos Humanos pela Universidade Federal de Rondônia, 2014/15. Professora do Curso de Direito da Faculdade Interamericana de Porto Velho (UNIRON). Professora do Curso de Direito da Faculdade de Rondônia (FARO). Elaborou e Coordenou o Curso de Pós-Graduação em Ciências Criminais na UNIRON no período de 17/04/2009 até abril 2010. Elaborou e Coordenou o Curso de Pós-Graduação em Direito e Gestão Ambiental na UNIRON no período de 25/09/2009 até 28/02/201r.Leciona em Cursos de PósGraduação nas áreas de Direito Penal, Segurança Pública e Ambiental. Membro do Conselho Editorial da Revista Jurídica da UNIRON. Parecerista da Revista Saberes da Amazônia da Faculdade Católica de Rondônia. Foi Chefe da Assessoria de Apoio para Assuntos Jurídicos da I7 $^{\underline{a}}$ Bda Inf S1 e Io Tenente do Exército Brasileiro (2011-2019) atuou para defesa da União junto à AGU/RO e participou de Operações Garantia da Lei e da Ordem e Garantia da Votação Apuração Eleitoral (Exército Brasileiro). Advogada com $\mathrm{OAB} / \mathrm{SP}$ e RO. Integrante do Núcleo Docente Estruturante e Professora do Curso Superior de Tecnólogo de Segurança Pública da Faculdade Católica de Rondônia - 2019. E-mail: andreia.almeida@uniron.edu.b
} 


\section{INTRODUÇÃO}

As constantes transformações vêm acontecendo no mundo, e as tecnologia é algo que está no nosso presente e estará no nosso futuro. Ela está tão integrada ao nosso cotidiano, que não é fácil viver sem ela. Cada vez mais dependemos da tecnologia para realizarmos nossas tarefas.

A maioria das pessoas preferem mandar uma mensagem via aplicativo, ou atualizar seu status social, do que ligar uma para outras. Tudo mudou, ao invés de simplesmente contarmos algo, nós demonstramos esse algo, seja através de fotos ou vídeos, afinal, uma imagem vale muito mais do que mil palavras. E a internet ficou sendo uma ferramenta tão importante. E um dos efeitos principais na era da informação é a constante perda da privacidade decorrente das variadas formas de comunicações disponíveis e que possibilitam o ser humano mostrar o seu melhor e o seu pior para muitas pessoas ao mesmo tempo, em diversos lugares do mundo, e em poucos instantes.

A segurança do anonimato e a interface impessoal, são fatores contribuintes para os crimes cibernéticos, principalmente os de caráter de exposição da privacidade alheia, e até mesmo da própria exposição. Cada vez mais jovem vem cometendo erros de não ter limites nas redes sócias no que diz respeito sobre os crimes cibernéticos, não havendo limites entre o certo e o errado.

Um dos crimes da modernidade e a Pornografia de Vingança, também conhecida como Pornografia de Revanche ou Pornografia de Revanchismo, vem do termo americano 'Revenge Porn', que apesar de ter acontecido antes mesmo da internet, somente alcançou proporções catastróficas, por conta da internet, e suas muitas formas de compartilhamento rápido e fácil.

A internet alcança mais de 150 países, agrupando mais de 300 milhões de computadores, é um amontoamento de computadores interconectadas de proporção mundial (DIZARD, 2000, p. 24). Foi a partir de 1995 que o Brasil teve as primeiras iniciativas de disponibilizar internet a toda a população.

Com toda a facilidade que a internet proporciona a maior preocupação é que, a exposição se tornou desregrada, quando alguém envia fotos ou vídeos comprometedores alguém esse alguém pode passar a terceiros e assim suscetivelmente, ocorrendo um repasse 
gigantesco, podendo gerar consequências que na maioria das vezes termina em litígio.(WANZINACK; SCREMIN, 2014, p.23).

$\mathrm{O}$ artigo foi dividido em duas partes, sendo que a primeira tratou de conceituar e apresentar em um primeiro momento, um breve histórico sobre crimes virtuais de modo genérico, e em um segundo momento, focar a Revenge Porn, Sextortion e estupro virtual, objetivando mostrar os crimes cibernéticos e suas leis em devesa.

Para atingir o objetivo proposto optou-se por desenvolver uma pesquisa de revisão bibliográfica pesquisa exploratório e descritiva, com abordagem qualitativa. Realizou-se pesquisa documental nos boletins de ocorrência na delegacia do município de Humaitá localizado na região sul do Estado do Amazonas dos anos de 2019, 2020 e 2021, na qual houve uma análise da jurisprudência nas esferas penais da Lei Maria da Penha, bem como do das Leis 13.718/2018, 12.737/2012 e do Projeto de Lei 5.555/2013, buscando uma reflexão do cenário atual da violência cibernética contra a mulher, assim como foi assistidos documentários sobre o tema, feito buscas sobre o assunto em sites, artigos dentre outros meios, para que assim seja explanado o assunto de maneira mais benéfica.

\section{CRIME VIRTUAL}

Os crimes virtuais são delitos praticados através da internet, com objetivo de atingir alguém, podendo ser uma pessoa específica ou um público ocasional. $O$ avanço da tecnologia e a facilidade do acesso à internet, tornou as pessoas mais vulneráveis aos crimes cibernéticos. "A ocorrência desses crimes apresenta um crescimento acentuado, seja pelo crescimento de usuários, pelas vulnerabilidades existentes na rede ou pela falta de atenção do usuário". (WENDT e NOGUEIRA JORGE, 2013, p. I)

Como bem nos assegura Sidow (2015) pode-se dizer que grande parte das vítimas dos crimes cibernéticos, são pessoas que utilizam o meio virtual, mas não tem um grande conhecimento sobre este ambiente e acabam se tornando vulneráveis. Neste contexto, fica claro que por esta falta de conhecimento, acabam incentivando a continuidade destes delitos. O mais preocupante, contudo, é constatar que a sociedade digital proporciona uma sensação de anonimato e liberdade para agir, que acaba gerando uma sensação de impunidade para quem utiliza de forma irresponsável para a prática de crimes. 


\subsection{Crimes Revenge Porn e Sexting}

O Revenge Porn é um crime, crime esse que afeta não somente a privacidade, atinge também a dignidade humana sendo o Sexting, existe hoje no Brasil legislação classificando tal ato como crime.

A palavra sexting significa sexo e texto, ou seja, como o nome já da a entender é a exposição de itens relacionados a sexualidade, fotos de nudez ou semi nudez a partir de computadores, celulares pelos meios que os mesmos oferecem (BARROS; RIBEIRO; QUADRADO, 2015, p. 1186).

Com essa propagação das redes sociais e as frequências de casos de violência contra a mulher por crimes virtuais vinculados a revenge porn vem crescendo muito em nosso país. O maior e principal propagador são homens motivados por vingança utilizando de material pornográfico, não consentido pela vítima, como meio para promover humilhação, e sofrimento psicológico. como o revege porn sendo um crime independendo da relação do criminoso com a vítima, podendo ainda incluir sexting sem envolvimento emocional de ambas as partes.

O maior problema dos crimes relacionados a Sexting e revenge porn são as consequências após a exposição e a maneira como o crime é julgado, pois ainda existem lacunas que precisam ser preenchidas, como o aumento da pena, as consequências para a vítimas são desastrosas, a vítima fica constrangida, fica exposta, vulnerável e com sentimento de ridicularização, tal crime vem sido discutido e exposto a pouco tempo, mesmo tendo pena prevista em Lei, ainda é praticado com muita frequência, devendo ser criados novos mecanismos de defesas como forma de prevenção a tal delito. Nosso objetivo é analisar os aspectos jurídicos das Leis 13.718/2018, $12.737 / 2012$ e 11.340/2006 e como eles atuam sobre crimes cibernéticos de violência moral, assim como a criação de novos mecanismos de defesas.

Cabe ressaltar a questão da limitação judicial da Lei 13.718/2018 para a resolução desses casos, não a caracterizando como um tipo de violência, que seria complementado caso Projeto de Lei 5.555/2013 fosse efetivado, podendo efetivar a jurisprudência do caso de maneira mais efetiva.

Com isso iremos relacionar o direito a dignidade humana à liberdade e segurança no ambiente virtual. Posteriormente compreender a aplicabilidade da lei sobre o revenge 
porn, verificando sua abrangência sobre as necessidades que os crimes cibernéticos demandam. Além de demonstrar a necessidade da aprovação do Projeto de lei 5.555/2013. Para assim incentivar mulheres a denunciarem abusos e crimes de violência na esfera virtual

Os resultados estão apresentados na forma de tópicos e desenvolvidos a seguir. A análise gerou um conhecimento classificado em duas categorias de acordo com a demonstração na Tabela i e 2 .

Tabela I: Procedimentos (Inquérito) - Violência doméstica

\begin{tabular}{|c|c|}
\hline & \\
\hline Ano & Ocorrência \\
\hline $\mathbf{2 0 1 9}$ & 95 \\
\hline $\mathbf{2 0 2 0}$ & 132 \\
\hline Janeiro a Agosto 2021 & 65 \\
\hline
\end{tabular}

Tabela 2: Ocorrência referentes à violência doméstica

\begin{tabular}{|c|c|}
\hline & \\
\hline Ano & Quantidade \\
\hline 2020 & I79 \\
\hline 2021 & 89 \\
\hline
\end{tabular}

Foi constatado que a violência doméstica são as mais frequentes. Na maioria dos casos, a violência doméstica teve seu registro e abriu-se inquérito e outras vezes não houve somente a ocorrência.

A análise do total de casos registrados no período de 2019 evidenciou o registro de 95 casos/ ano, registraram um único episódio de violência doméstica. Já no ano no período de 2020 evidenciou 179 ocorrência e. dessa ocorrência 132 abriu-se inquérito. Em 202I as ocorrências foram de 89 sendo que de janeiro a agosto 65 casos inquérito

Em todo mundo, pelo menos uma em cada três mulheres já foi espancada, coagida ao sexo ou sofreu alguma outra forma de abuso durante a vida. $\mathrm{O}$ agressor é, geralmente, um membro de sua própria família. A violência contra as mulheres é o tipo mais generalizado de abuso dos direitos humanos no mundo e o menos reconhecido. 
A relação com a dignidade humana é indispensável para a compreensão dessas infrações como crimes, para Silva (1988), dignidade é considerada um atributo intrínseco da essência humana, o qual possui conexões com a própria natureza, por aspectos físicos, psicológicos e sociológicos, não possuindo substituição que a seja equivalente.

Os achados do estudo revelaram que as mulheres que foram vítimas de violência denunciaram seus agressores no município. Entretanto, os números tendem a não retratar a real situação da violência no município, visto que de acordo com o Ministério da Saúde apenas I0\% das brasileiras vitimizadas pela violência registram as agressões no sistema judiciário ou de saúde, resultando em subnotificação estimada de 90\%.

Quanto aos crimes virtuais, de antemão, é importante destacar que o município é deficiente no que concerne a segurança no ambiente virtual, uma vez que não possui delegacia especializada desta natureza para abranger as demandas de todo o município. Entretanto, esta carência de efetivo policial na prevenção e repressão aos crimes tecnológicos não é restrito e específico no município, mas reflete uma deficiência nacional, o que se extrai dos dados mais recentes conhecidos sobre quantidade de delegacias especializadas em ciberneticos fornecidos pela Agência Nacional de Telecomunicações.

O Sexting e RevengePorn é de certa maneira a vingança virtual e no início do século $\mathrm{XX}$ aconteceu notáveis crescimentos na área da tecnologia, mais ainda na área da internet. Com tais acontecimentos foi inevitável não acontecer o crescimento dos vínculos virtuais alterando assim o modo como os indivíduos se socializam e de registro em delegacias, pois na pesquisa não se ver esses registros.

Proliferou uma nova modalidade de expressão sexual, o chamado sexting, meio de relação de caráter sexual entre pessoas através de aparelho eletrônico. Dentro dessa categoria, há o chamado revenge porn, ato de disseminar informações pessoais, majoritariamente de mulheres, de natureza sexual,

[...] tal situação trata-se da chamada pornografia da vingança, que nada maissignifica do que o ato de expor na internet fotos e/ou vídeos íntimos de terceiros sem o seu consentimento, com o objetivo exclusivo de constranger e humilhar, através da reprodução, a vítima cujas cenas de nudez ou ato sexual participou. (DOMINGUES, 2018, p. I).

De acordo com Lima (2012, online), os crimes digitais são: 
[...] qualquer conduta humana (omissiva ou comissiva) típica, antijurídica e culpável, em que a máquina computadorizada tenha sido utilizada e, de alguma forma, tenha facilitado de sobremodo a execução ou a consumação da figura delituosa, ainda que cause um prejuízo a pessoas sem que necessariamente se beneficie o autor ou que, pelo contrário, produza um benefício ilícito a seu autor embora não prejudique de forma direta ou indireta à vítima.

Desde a disseminação das novas tecnologias de comunicação a facilidade na troca de informações resultou em novos tipos de infração à direitos fundamentais normatizados na Constituição Federal.

\section{CONSIDERÇÕES FINAIS}

Infelizmente, a violência contra a mulher é uma realidade presente desde os primórdios da humanidade, e principalmente em países dotados de distintos regimes econômicos e políticos, uma prática que precisa ser combatida por todos.

A violência sofrida pela condição de se ser mulher, sem distinção de raça, classe social, religião, idade ou qualquer outra condição, é produto de um sistema social que subordina o sexo feminino. A finalidade é que o agressor se torne o disciplinador, o dominador e dessa forma intimidar a mulher.

Neste sentido, com base na análise dos dados, por meio dos boletins de ocorrência, colhidos na Delegacia do Município de Humaitá, foi possível compreender que a violência contra mulher ainda é ativa, principalmente a violência doméstica.

Como ficou evidenciado nos casos registrados entre anos de 2019 e 2020 constatouse que houve um crescente número de violência contra a mulher. E esta violência foi cometida por membro da família, companheiro ou marido. Embora, no ano de 202I tenha diminuído os casos, ainda é um número insuficiente para superar a violência que é cometida contra a mulher.

A pesquisa também mostrou que as mulheres que sofreram violência doméstica denunciaram seus agressores, embora não retrate a real situação que acontece no município. Isso porque são poucas as mulheres que registram as agressões. E em outros casos elas desistem de dar continuidade no processo judicial.

No que se refere aos crimes virtuais percebemos que o município não possui uma delegacia especializada nestes crimes. De forma que dificulta bastante catalogar os crimes 
dessa natureza. Lembramos que esta deficiência não é somente municipal, mas, principalmente, nacional.

De modo que os crimes como Sexting e RevengePorn não foram registrados. Mas, com o advento proliferado da internet no final do século XX e início do século XXI e com vários crimes que acontecem na internet não será surpresa que se porventura forem registrados no município cremes dessa natureza.

Portando, a pesquisa é relevante por contribuir com informações que ajudarão na reflexão e combate sobre as mulheres que sofrem ou sofreram algum tipo de violência, seja doméstica ou virtual. E dessa forma qualificar os órgãos competentes para que sejam mais efetivos no combate desses crimes, alertando e notificando todas as situações de violência contra a mulher

\section{REFERÊNCIAS}

CRESPO. Marcelo. Sexting e revenge porn: porque precisamos falar sobre isso. Ciências Criminais. 2015.

CRESPO. Marcelo. Revenge porn: a pornografia da vingança. Jus Brasil. 20I4. Gleick Meira. SANTIAGO. Tatiany Silva. Crimes contra a honra na rede social Facebook. Âmbito Jurídico. 2019. Disponível em: https://ambitojuridico.com.br/cadernos/direitopenal/crimes-contra-a-honra-na redesocial-facebook/. Acesso em: 05. março.2020

Decreto no 1.973, de Io de agosto de 1996: Promulga a Convenção Interamericana para Prevenir, Punir e Erradicar a Violência contra a Mulher, concluída em Belém do Pará, em 9 de junho de 1994. 1996.

FERNANDES. Lauren. Exposição nas redes sociais sem autorização. JUS BRASIL. 2018.

LIMA. Janaina Fernanda. Pornografia não consensual e a carência de tutelas jurídicas e emancipatórias de gênero. Jus. 2018.

MATIAS-PEREIRA, José. Manual de metodologia da pesquisa científica. 4. ed. [3. Rempr.]. São Paulo: Atlas, 2019.

MEZZAROBA, Orides \& MONTEIRO, Cláudia Servilha. Manual de metodologia da pesquisa no direito. 8. ed. São Paulo: Saraiva Educação, 2019. [BIBLIOTECA DIGITAL]'

SYDOW, S. T. Crimes informáticos e suas vítimas. $2^{\underline{a}}$ Edição. ed. São Paulo: Saraiva, 2015 .

WENDT, E.; NOGUEIRA JORGE, H. V. Crimes cibernéticos: ameaças e procedimentos de investigação. $2^{\underline{a}}$. ed. Rio de Janeiro: Brasport, 2013. 